\title{
HUBUNGAN KOMUNIKASI TERAPEUTIK DALAM PEMBERIAN OBAT DENGAN TINGKAT KEPUASAN PASIEN
}

\section{The Relationship of Therapeutic Communications In Providing Medicines And The Level of Patient Satisfaction}

\author{
Levi Tina Sari ${ }^{1}$, Ervi Suminar ${ }^{2}$ \\ ${ }^{1}$ Prodi Kebidanan Stikes Patria Husada Blitar \\ ${ }^{2}$ Prodi Keperawatan Universitas Muhammadiyah Gresik \\ Alamat Korespondensi : STIKes Patria Husada \\ Jl.Sudanco Supriyadi No.168 Blitar, Jawa Timur - Indonesia \\ Email : tinasari.levi@gmail.com
}

\begin{abstract}
ABSTRAK
Kepuasan adalah perasaan senang atau kecewa seseorang yang muncul setelah membandingkan antara persepsi atau kesannya terhadap kinerja atau hasil suatu produk dan harapan-harapannya. Penelitian ini bertujuan untuk mengetahui hubungan komunikasi terapeutik dalam pemberian obat dengan tingkat kepuasan pasien di Irna A RSUD Syarifah Ambami Rato Ebu Kabupaten Bangkalan.

Penelitian ini menggunakan desain Analitik Corelative dengan pendekatan Cross sectional.Populasi penelitian adalah semua pasien yang dirawat di Irna A RSUD Syarifah Ambami Rato Ebu Kabupaten Bangkalan sebanyak 63 pasien. Sedangkan sampel penelitian sebanyak 54 pasien.Cara pengambilan sampel menggunakan non probability sampling dengan teknik kuota sampling.Data dikumpulkan menggunakan kuesioner kemudian dianalisa menggunakan Spearman Rank dengan $\alpha=0,05$.

Hasil penelitian, dari 34 orang dengan komunikasi terapeutik kurang, 13 pasien $(38,2 \%)$ merasa kurang puas, 19 pasien $(55,9 \%)$ merasa cukup puas dan 2 pasien $(5,9 \%)$ merasa puas. UjiSpearman Rank menunjukkan $\rho_{\text {value }}=0,001<\alpha=0,05$ yang berarti ada hubungan antara komunikasi terapeutik dalam pemberian obat dengan tingkat kepuasan pasien di Irna A RSUD Syarifah Ambami Rato Ebu Kabupaten Bangkalan.
\end{abstract}

Kata Kunci: kepuasan, komunikasi terapeutik, obat, pasien

\section{ABSTRACT}

Satisfaction is someone's feeling happy or disappointed who emerged after comparing the perception or impression of the performance or the result of a product and its expectations. This study aimed to analyze the relationship between therapeutic communication in drug delivery to the patient satisfaction level in Irna A Syarifah Ambami Rato Ebu hospitals Bangkalan.

The design of this study Analytical Corelative using cross sectional approach. The study population was all patients admitted to the Irna A Syarifah Ambami Rato Ebu hospitals Bangkalan were 63 respondents. While samples are 54 respondents. How sampling non probability sampling with quota sampling technique. The independent variable is communication therapeutic nurse in drug delivery and dependet variable is the level of patient satisfaction. Data were collected using a questionnaire and analyzed using Spearman Rank with $\alpha=0.05$.

The results of the study in August 2017, showed that nurses who performed therapeutic communication in drug delivery well and satisfied as many as 2 respondents (5.9\%), and therapeutic communication in drug delivery nurses who did less and almost all families of patients feel less satisfied as many as 13 respondents (38.2\%). Spearman Rank indicates that $\rho$ value $=0.001<\alpha=$ 0.05 , which means that there is a relationship between therapeutic communication in drug delivery to the patient satisfaction level in Irna A Syarifah Ambami Rato Ebu hospital Bangkalan.

Keyword: patient, satisfaction, communication therapeutic, drug 


\section{PENDAHULUAN}

Komunikasi terapeutik diterapkan oleh perawat dalam berhubungan dengan pasien untuk meningkatkan rasa saling percaya dan apabila tidak diterapakan akan menganggu hubungan terapeutik yang berdampak pada ketidakpuasan pasien. Pasien akan merasa puas ketika kinerja layanan kesehatan yang diperolehnya sama atau melebihi harapannya dan sebaliknya, ketidak puasan atau perasaan kecewa pasien akan muncul apabila kinerja layanan kesehatan yang diperolehnya itu tidak sesuai dengan harapannya (Machfoedz, 2009).

Ada 5 kesenjangan yang menyebabkan ketidak puasan pasien. Yang pertama kesenjangan antara harapan pelayanan dengan persepsi managemen, managemen tidak memahami apa yang menjadi keinginan pelanggan. Pada pelaksanaan cara berkomunikasi perawat tidak sesuai dengan keinginan pelanggan. Kedua kesenjangan antara persepsi manajemen dengan spertifikasi kualitas jasa. Manajemen tidak memahami keinginan pelanggan dan tidak menetapkan dalam standar pelaksanaan. Ketiga kesenjangan antara pelayanan dengan spesifitas. Keempat kesenjangan antara pelayanan dan komunikasi external. Hal ini komunikasi perawat tidak sesuai dengan harapan klien. Kesenjangan yang kelima kesenjangan harapan dan kualitas pelayanan yang diterima pelanggan (Potter \& Perry, 2010).

Data hasil survei tingkat kepuasan pasien terhadap pelaksanaan komunikasi terapeutik perawat di Instlasi Ruang Rawat Inap RSUD Labuang Baji Makasar tahun 2013 adalah $68,8 \%$ dan belum memenuhi standart kepuasan pelanggan rawat inap berdasarkan Kepmenkes No.129 tahun 2008 yaitu kurang lebih $90 \%$, hasil wawancara peneliti pada tgl 15 Februari 2013 dengan Kepala Keperawatan RSUD Labuang Baji, dapat diketahui bahwa masalah yang paling sering di keluhkan pasien salah satunya yaitu ketidakjelasan informasi dari perawat dan keluhan pasien yang kadang tidak ditanggapi (Nastsir, 2011).

Data mengenai kesalahan akibat komunikasi di RSUD Cengkareng adalah sebanyak 17 insiden pada tahun 2012 sedangkan pada tahun 2013 sebanyak 22 insiden, insiden tersebut terjadi karena kesalahan dalam menerima informasi baik obat maupun tindakan (Susiwi, 2014)

Berdasarkan studi pendahuluan yang dilakukan di IRNA A RSUD Syarifah Ambami Rato Ebuh Bangkalan pada tanggal 07 November 2016 dari hasil kuesioner yang dibagikan kepada 10 orang pasien di IRNA A RSUD Syarifah Ambami Rato Ebuh Bangkalan diperoleh 2 orang mengatakan kurang puas atas komunikasi yang diberikan perawat pada saat pemberian obat kepada pasien, karena kurangnya kesempatan bagi pasien untuk lebih bebas bertanya tentang obat apa yang diberikan, fungsi obat beserta efek samping dari obat yang diberikan dan sikap perawat yang tidak ramah, 6 orang mengatakan cukup puas atas pelayanan yang diberikan perawat pada saat pemberian obat yang jelas, dan sikap pedulinya perawat tehadap pasien, dan 2 orang mengatakan puas dengan komunikasi terapeutik dalam pemberian obat kepada pasien. Hal ini 
menunjukkan komunikasi terapeutik dalam pemberian obat belum dijelaskan dengan maksimal terhadap pasien.

Penyebab dari ketidak puasan, karena perawat dalam memberikan atau menjelaskan informasi dengan komunikasinya kurang begitu baik dan sikap yang kurang baik pula. Hal ini memungkinkan karena perawat memang mempunyai suatu hambatan dalam proses komunikasi dengan pasien (Machfoedz, 2009). Bahasa yang dipergunakan atau yang disampaikan kurang jelas atau bahasa yang dipergunakan tidak mudah untuk dimengerti. Ada beberapa perawat sewaktu memberikan obat kepada pasien tidak menggunakan komunikasi terapeutik yang baik. Misalnya saat memberikan obat perawat memanggil nama pasien dengan berteriak dan membentak dengan nada tinggi dan menakut-nakuti pasien supaya pasien segera minum obat (Suryani, 2008).

Dampak yang dapat ditimbulkan dalam pemberian obat dengan komunikasi terapeutik yang kurang baik antara lain bias menimbulkan kesalah pahaman antara perawat dengan pasien. Perawat harus bisa menggunakan bahasa yang mudah dimengerti oleh pasien, dimana dalam menerangkan tindakan komunikasi adalah menjawab pertanyaan "siapa yang menyampaikan, apa yang disampaikan, melalui saluran apa, kepada siapa, dan apa pengaruhnya". Dan perawat yang enggan berkomunikasi dengan menunjukkan raut muka yang tegang juga akan berdampak kepada pasien. Pasien akan merasa tidak nyaman bahkan terancam dengan sikap perawat. Kondisi seperti itu tentunya akan sangat berpengaruh terhadap kesembuhan pasien.

\section{METODE PENELITIAN}

Dalam penelitian ini jenis penelitian yang digunakan yaitui“Analitik Corelative Cross Sectional Non Experimental".Analitik korelatif artinya penelitian bertujuan untuk melakukan analisis hubungan atau perbedaan antar variable sedangkan cross sectional.

Populasi dalam penelitian ini adalah semua pasien yang mendapat perawatan diruang IRNA A RSUD Syarifah Ambami Rato Ebuh Bangkalan. Pasien yang di rawat diruang IRNA A RSUD Syarifah Ambami Rato Ebu Bangkalan pada bulan November tahun 2016 - Januari tahun 2017 sebanyak 189 orang.Estimasi atau perkiran populasi dalam penelitian berjumlah 63 orang yang memiliki criteria inklusi seperti:

1. Bersedia menjadi responden

2. Di rawat di IRNA A

3. Di rawat lebih dari 5 hari

4. Usia di atas 17 tahun

Pada penelitian ini sampel dari keseluruhan populasi yang memenuhi kriteria sampel yaitu pasien yang dirawat di IRNA A RSUD Syarifah Ambami Rato Ebu Bangkalan sebanyak 54 orang.

Pada penelitian ini teknik sampling yang digunakan adalah non probabiliy sampling dengan teknik kuota sampling.Pembagian dalam pemilihan responden dalam penelitian ini yaitu dari satu orang pasien di IRNA A. 
HASIL

\section{Data Umum}

Tabel 1. Distribusi frekuensi pasien berdasarkan jenis kelamin dan usia

\begin{tabular}{lcc}
\hline $\begin{array}{l}\text { Jenis } \\
\text { Kelamin }\end{array}$ & $\begin{array}{l}\text { Frekuensi } \\
\text { (f) }\end{array}$ & \multicolumn{2}{l}{$\begin{array}{l}\text { Persentase } \\
(\%)\end{array}$} \\
\hline Laki-laki & 35 & 64,8 \\
\hline Perempuan & 19 & 35,2 \\
\hline Usia & 1 & 1,9 \\
\hline $10-19$ & 14 & 25,9 \\
\hline $20-29$ & 18 & 33,3 \\
\hline $30-39$ & 14 & 25,9 \\
\hline $40-49$ & 6 & 11,1 \\
\hline $50-59$ & 1 & 1,9 \\
\hline $60-69$ & &
\end{tabular}

Sumber: Data Primer: Agustus 2017

Berdasarkan tabel 1 sebagian besar pasien berjenis kelamin Laki-laki sebanyak 35 responden $(64,8 \%)$, sedangkan umur pasien paling banyak adalah 30-39 tahun yaitu sebanyak 18 orang $(33,3 \%)$.
Tabel 2. Distribusi frekuensi komunikasi terapeutik perawat

\begin{tabular}{lcc}
\hline $\begin{array}{l}\text { Komunikasi } \\
\text { Terapeutik }\end{array}$ & $\begin{array}{l}\text { Frekuensi } \\
\text { (f) }\end{array}$ & $\begin{array}{l}\text { Presentase } \\
\text { (\%) }\end{array}$ \\
\hline Baik & 8 & 14,8 \\
\hline Cukup & 12 & 22,2 \\
\hline Kurang & 34 & 63 \\
\hline Jumlah & 54 & 100 \\
\hline Sumber: Data Primer: Agustus 2017 &
\end{tabular}

Berdasarkan tabel 2 menunjukkan sebagian besar komunikasi terapeutik yang dilakukan perawat adalah kurang, yaitu sebanyak 34 orang $(63 \%)$.

Tabel 3. Distribusi frekuensi kepuasan pasien

\begin{tabular}{lcc}
\hline $\begin{array}{l}\text { Tingkat } \\
\text { Kepuasan }\end{array}$ & Frekuensi & $\begin{array}{l}\text { Presentase } \\
(\%)\end{array}$ \\
\hline Puas & 16 & 29,6 \\
\hline Cukup Puas & 29 & 53,7 \\
\hline Kurang Puas & 9 & 16,7 \\
\hline Jumlah & 54 & 100 \\
\hline Sumber: Data Primer: Agustus 2017 &
\end{tabular}

Berdasarkan tabel 3 menunjukkan tingkat kepuasan pasien sebagian besar adalah cukup puas yaitu sebesar 29 orang $(53,7 \%)$.

\section{Data Khusus}

Tabel 4. Tabulasi Silang Hubungan Komunikasi Terapeutik Dalam Pemberian Obat Terhadap Tingkat Kepuasan pada Pasien

\begin{tabular}{|c|c|c|c|c|c|c|c|c|}
\hline \multirow{3}{*}{$\begin{array}{l}\text { Komunikasi } \\
\text { Terapeutik }\end{array}$} & \multicolumn{6}{|c|}{ Kepuasan Pasien } & \multirow{2}{*}{\multicolumn{2}{|c|}{ Total }} \\
\hline & \multicolumn{2}{|c|}{$\mathbf{K}$} & \multicolumn{2}{|c|}{$\mathbf{C}$} & \multicolumn{2}{|r|}{$\mathbf{P}$} & & \\
\hline & $\mathbf{N}$ & $\%$ & $\mathbf{N}$ & $\%$ & $\mathbf{N}$ & $\%$ & $\mathbf{N}$ & $\%$ \\
\hline Baik & 0 & 0 & 3 & 37,5 & 5 & 62,5 & 8 & 100 \\
\hline Cukup & 3 & 25 & 7 & 58,3 & 2 & 16,7 & 12 & 100 \\
\hline Kurang & 13 & 38,2 & 19 & 55,9 & 2 & 5,9 & 34 & 100 \\
\hline Total & 16 & 29,6 & 29 & 53,7 & 9 & 16,7 & 54 & 100 \\
\hline
\end{tabular}

Dari hasil tabulasi silang menunjukkan bahwa sebanyak 34 orang dengan komunikasi terapiutik kurang, 13 pasien $(38,2 \%)$ merasa kurang puas, 19 pasien $(55,9 \%)$ merasa cukup puas dan 2 pasien $(5,9 \%)$ merasa puas.
Berdasarkan hasil uji Spearman Rank di dapatkan hasil $(p)$ 0,001 dan ( $\alpha$ ) 0,05 sehingga $p<\alpha(0,001<0,05)$. Hal ini berarti H0 ditolak dan H1 diterima, maka ada hubungan komunikasi terapeutik perawat terhadap tingkat kepuasan keluarga pasien di Irna A 
RSUD Syarifah Ambami Rato Ebu Kabupaten Bangkalan.

\section{PEMBAHASAN}

\section{Komunikasi Terapeutik}

Berdasarkan hasil penelitian bahwa sebagian besar komunikasi terapeutik dalam pemberian obat yang dilakukan perawat terhadap pasiendi Irna A RSUD Syarifah Ambami Rato Ebu Kabupaten Bangkalan pada bulan Agustus 2017 dengan kriteria baik sebanyak $8(14,8 \%)$ kriteria cukup sebanyak $12(22,2 \%)$ kriteria kurang sebanyak 34 (63\%). Tingkat pendidikan yang paling banyak SD 20 orang $(37 \%)$.

Kebutuhan utama keluarga diruang perawatan adalah informasi tentang kondisi pasien.tim perawatan perlu menfasilitasi untuk melakukan komunikasi yang aktif dengan membuat jadwal pertemuan atau menyediakan waktu kapan saja keluarga perlukan karena dengan informasi yang sulit akan meningkatkan kecemasan dan ketidakpuasan keluarga. Selain itu sikap yang penuh perhatian, empati, dan ramah saat menyampaikan informasi tersebut sangat diharapkan oleh keluarga (Hadi, 2007)

Komunikasi terapeutik kurang dapat disebabkan oleh beberapa faktor seperti pendidikan pasien yang sebagian besar berpendidikan SD sebanyak 20 orang. Hal ini dapat menyebabkan gangguan dalam penerimaan informasi antara perawat dengan pasien, selain itu, faktor yang lain adalah pasien kurang aktif bertanya mengenai tujuan pengobatan dan jenis obat. Pada dasarnya perawat sudah menjelaskan tujuan obat yang di berikan namun tidak secara lengkap dan perawat juga kurang memberi kesempatan kepada pasien untuk bertanya, beberapa perawat enggan menjalaskan keseluruhan proses pengobatan dan jadwal kunjungan dokter apabila pasien tidak bertanya.

Karena pada saat berbicara tentang pemberian obat perawat diam dan memperhatikan, perawat tidak memutus pembicaraan anda saat anda sedang berbicara,jarang menawarkan untuk bertanya tentang masalah pemberian obat. Sehingga komunikasi terapeutik dalam pemberian obat yang dilakukan perawat tidak maksimal terhadap pasien yang akan menyebabkan pasien kecewa dan timbul perasaan tidak puas.

Komunikasi terapeutik cukup disebabkan karena perawat memperkenalkan namanya pada saat pemberian obat, perawat menanyakan topik pembicaraan yang merupakan kebutuhan utama saat ini untuk didiskusikan saat pemberian obat, perawat tidak membicarakan topik yang tidak sesuai dengan masalah saat pemberian obat.

Komunikasi terapeutik baik dikarenakan karakteristik Pasien lebih aktif dalam bertanya dan lebih terbuka dalam mengungkapkan keluhannya, Sehingga beberapa perawat melakukan prosedur pemberian obat dari memberi salam pada saat pemberian obat, menanyakan nama panggilan kesukaan pasien pada saat pemberian obat, dan mengakhiri wawancara atau komunikasi dengan cara yang baik, saat berkomunikasi perawat mendengarkan dan memberikan perhatian serius terhadap apa yang dikeluhkan, menyapa/tersenyum ketika pertama bertemu 
pasien dan keluarga, menanyakan keadaan pasien, menyampaikan informasi tentang keadaan/kondisi pasien terhadap keluarga dan memberikan saran pada pasien dan keluarga tentang tindak lanjut yang akan dilakukan, dengan skor tertinggi dalam mengisi kuesioner 58.

RSUD Syarifah Ambami Rato Ebu Bangkalan telah mempunyai SOP untuk setiap tidakan termasuk tindakan pemberian obat. SOP ini berada didekat pintu menuju kepala ruangan. Sehingga tidak semua perawat dapat memperhatikan, walaupun SOP sudah pernah disosialisasikan. Kurangnya komitmen perawat dalam melakukan prosedur pemberian obat menyebabkan kurangnya komunikasi terapeutik yang terjalin. Pemberian sanksi apabila tidak melakukan prosedur sesuai SOP tentunya akan membantu dalam proses peningkatan kualitas pelayanan dan mencegah terjadinya kesalahan dalam pemberian obat.

\section{Kepuasan Pasien}

Berdasarkan hasil penelitian bahwa sebagian besar pasien di Irna A RSUD Syarifah Ambami Rato Ebu Kabupaten Bangkalan pada bulan Agustus 2017 dengan tingkat kepuasan puas sebanyak $16(29,6 \%)$, dengan tingkat kepuasan cukup puas sebanyak 29 (53,7\%), dengan tingkat kepuasan kurang puas sebanyak $9(16,7 \%)$.

Faktor-faktor yang mempengaruhi kepuasan yaitu informasi (komunikasi terapeutik perawat) dimana perawat dalam memberikan informasi dan penjelasan dapat dilakukan dengan baik apabila didukung oleh pelaksanaan komunikasi yang efektif, pasien dan keluarga akan merasa puas ketika kinerja layanan kesehatan yang diperolehnya sama atau melebihi harapannya dan sebaliknya, emosional adalah perasaan subjektif seseorang mengenai peristiwa tertentu dan juga cara seseorang bersosialisasi atau berkomunikasi dengan orang lain, keluarga dan pasien akan merasa puas bila hasil evaluasi mereka menunjukkan bahwa produk atau jasa yang digunakan berkualitas jika kinerja atau produk lebih tinggi dari harapan konsumen maka konsumen akan mengalami kepuasan, kualitas pelayanan, dan harga (Purwanto, 2007).

Hal ini sesuai dengan teoribahwa dalam penggunaan peralatan yang modern, fasilitas yang lengkap, kerapian dan kebersihan perawat maupun ruangan akan menciptakan seseorang tertarik dengan pelayanan yang diterimanya (Susiwi, 2014).

Pasien yang merasa kurang puas dalam pelayanan keperawatan disebabkan karena informasi yang diberikan perawat kurang jelas dalam hal obat yang diberikan, kurangnya ketersediaan obat di apotik rumah sakit sehingga pasien atau keluarga pasien harus mencari sendiri obat tersebut ke apotik yang lain, dan kurangnya ketanggapan perawat dalam melayani pasien misalnya pada saat pasien menekan tombol bel panggilan untuk perawat, perawat tidak segera datang keruangan pasien.

Pasien yang merasa cukup puas dalam pelayanan keperawatan di sebabkan karena sikap perawat saat melayani pasien cukup ramah, perawat hanya menjawab pertanyaan pasien dengan ramah apabila pasien bertanya tentang obat yang diberikan oleh perawat, 
sebagian perawat memberikan rasa nyaman sehingga pasien merasa tenang dan perwat dapat memberikan keyakinan kepada pasien bahwa perawat dapat mengatasi masalah yang dihadapi pasien.

Pasien yang merasa puas dengan beberapa faktor yaitu faktor Informasi komunikasi terapeutik perawat dimana perawat dalam memberikan informasi jelas dan mudah di mengerti oleh pasien dan keluarga pasien, faktor pelayanan yang diberikan perawat disebabkan karena apa yang mereka dapatkan sesuai dengan harapan untuk mendapatkan pelayanan yang terbaik dari petugas. Kepuasan tersebut timbul dari adanya keandalan kesigapan dan tanggung jawabpetugas dalam memberikan pelayanan kesehatan, seperti sifat perawat kepada pasien, penampilan perawat saat memeriksa sangat rapi dan sopan, kelengkapan obat yang disediakan perawat, kesigapan perawat apabila dibutuhkan oleh pasien, kerutinan perawat mengobservasi keadaan pasien, memberikan kenyamanan dan rasa aman selama dirawat di rumah sakit, kesediaan perawat menanggapi keluhan pasien dan keluarga, dan ketersediaan waktu perawat untuk pasien dan keluarga pasien.

RSUD Syarifah Ambami Rato Ebu Bangkalan telah memiliki apotik rumah sakit sendiri namun kurangnya ketersediaan obat di apotik rumah sakit harus segera diatasi agar tidak menyebabkan kesulitan bagi pasien atau keluarga pasien untuk mencari sendiri obat tersebut ke apotik lain, namun apabila benar obat tersebut tidak tersedia di apotik rumah sakit setidaknya perawat memberitahu dengan jelas kepada pasien atau keluarga pasien harus membeli obat tersebut di apotik mana menyediakan obat tersebut sehingga pasien atau keluarga pasien tidak kesulitan.

Pasien akan senantiasa merasa aman jika mendapatkan jaminan yang sesuai harapannya. Jaminan tersebut berupa jaminan keamanan pelayanan maupun jaminan kepercayaan pelayanan. Pasien dan keluarga pasien akan merasa puas jika dilayani dengan baik oleh perawat yang memiliki tingkat kompetensi dan mampu memberi rasa aman.

\section{Hubungan Komunikasi Terapeutik Dalam Pemberian Obat Terhadap Kepuasan Pasien}

Dari hasil tabulasi silang menunjukkan bahwa sebanyak 34 orang dengan komunikasi terapeutik kurang, 13 pasien $(38,2 \%)$ merasa kurang puas, 19 pasien (55,9\%) merasa cukup puas dan 2 pasien $(5,9 \%)$ merasa puas.

Hasil penelitian ini sejalan dengan penelitian oleh (Ibrahim, 2011), tentang Hubungan Pelaksanaan Komunikasi Terapeutik Pemberian Obat dengan Tingkat Kepuasan Pasien di Ruangan rawat inap Melati di RSUD Subang tahun 2011 menjelskan lebih dari separuh responden yang merasa puas terhadap komunikasi yang diterapkan oleh perawat terutama dalam pemberian obat, perawat masuk ruangan dengan mengucapkan salam, perawaat menayakan keadaan pasien dan pada fase pemberian obat selanjutnya perawat membuat kontrak waktu untuk pertemuan selanjutnya.

Pelaksanaan komunikasi terapeutik dalam pemberian obat perawat mampu 
mendatangkan kepuasan pasien, karena dengan komunikasi yang baik tersebut, pasienakan merasa nyaman dan tentram berada di ruangan perawatan, sehingga pada akhirnya mereka merasa puas dengan apa yang didapatkan dalam pelayanan kesehatannya. Keberhasilan pelaksanaan komunikasi terapeutik dan komunikasi terapiutik dalam pemberian obat dapat dilihat dari jumlah pasien yang bersedia dirawat dan kepuasan yang dirasakan pasien. Keberhasilan ini dapat diukur dengan out-put. Hal tersebut tidak lepas dari kewajiban perawat dalam menerapkan komunikasi terapeutik terhadap semua pasien. Komunikasi terapeutik dalam pemberian obat yang bermutu adalah komunikasi yang dilakukan berdasarkan standar operasional dandapat memuaskan pasien (Koe, 2013).

Hal ini didukung oleh teori yang menyatakan bahwa pelaksanaan komunikasi terapeutik dalam pemberian obat sangat berpengaruh terhadap kepuasan pasien sehingga dapat pula mempengaruhi jumlah pasien yang bersedia dirawat di rumah sakit tersebut (Hadi, 2007). Semakin baik komunikasi terapeutik dalam pemberian obat yang dilaksanakan maka semakin puas pasien dan keluarga dalam menerima sehingga akan meningkatkan angka kunjungan pasien ke Rumah Sakit sehingga target bisa dicapai seluruhnya. Dan kenyamanan dalam segi kesehatan terutama dalam pemberian obat pada pasien akan terjaga dari resiko ancaman kekeliruan dalam pemberian obat di rumah sakit.

Dari penelitian ini dapat dilihat perawat sudah melakukan komunikasi terapeutik dalam pemberian obat tapi masih ada pasien yang kurang puas, bisa disebabkan karena faktor emosional dari pasien, dikarenakan perawat jarang memberikan salam ketika akan memberikan obat, jarang memperkenalkan namanya ketika akan memberikan obat, hal tersebut menjadi acuan bagi pasien walaupun komunikasi terapeutik dalam pemberian obat dilakukan perawat tapi pasien masih ada yang tidak puas.

Dari penelitian ini dapat dilihat perawat yang kurang melakukan komunikasi terapeutik dalam pemberian obat, tapi masih ada pasien yang cukup puas. Hal ini bisa disebabkan seperti adayanya perawat yang penampilanya rapi dan sopan ketika dalam pemberian obat, perawat yang selalu menjelaskan manfaat obat kepada pasien, kerutinan perawat dalam memberikan obat kepada pasien.

Dari segi komunikasi memang kurang puas tapi mereka puas dari segi pelayanan dan ruangan seperti perawat ramah saat menyapa pasien dan keluarga pasien, Tersedianya kamar mandi yang lengkap untuk pasien dan keluarga pasien, serta kemudahan dalam biaya bagi pasien yang menggunakan akses BPJS atau Kartu Sehat.

\section{KESIMPULAN}

Ada hubungan antara komunikasi terapeutik perawat terhadap tingkat kepuasan pasien yang dirawat di Irna A RSUD Syarifah Ambami Rato Ebu Kabupaten Bangkalan.

\section{SARAN}

Agar para perawat dapat menyadari tentang pentingnya komunikasi terapeutik, 
sehingga dengan menerapkan komunikasi

teraupetik yang akan berdampak positif terhadap pelayanan kesehatan yang diberikan.

RSUD Syarifah Ambami Rato Ebu Bangkalan harus menerapkan kembali SOP dalam pemberian obat dan meletakkan SOP tersebut di tempat yang mudah terbaca oleh perawat.

\section{DAFTAR PUSTAKA}

Hadi, S. (2007). Mengkur Kepuasan Pelanggan.

Ibrahim. (2011). Hubungan Pelaksanaan KomunikasiTeraupetik Perawat Dengan Tingkat Kepuasan Pasien di Ruangan rawat inap Melati di RSUD Subang. http:www.elsevier.com/iccn.

Koe, R. . (2013). Komunikasi Terapeutik: Pendekatan Praktis Praktisi Kesehatan. Graha Ilmu.

Machfoedz, M. (2009). Komunikasi Keperawatan: Komunikasi Terapeutik. Gambika.

Nastsir, A. D. (2011). Komunikasi Dalam Keperawatan Teori dan Aplikasi. Salemba Medika.

Potter \& Perry. (2010). Buku Ajar Fundamental Keperawatan. Edisi $4 \mathrm{Vol}$ 1. EGC.

Purwanto. (2007). Metodelogi Penelitian Kuantitatif. Pustaka Pelajar.

Suryani. (2008). Komunikasi Terapeutik:Teori dan Praktik. EGC.

Susiwi. (2014). Hubungan antara perawat dalam serah terima dengan kejadian keselamatan pasien d ruang inap pepaya di RSUD Cengkareng Jakarta Barat. Universitas Esa Unggul. 